\title{
Tracking Required Organizational Practices Related to Processes Involving Medications
}

\author{
Mits Miyata and Janice Munroe
}

\section{INTRODUCTION}

Tn 2008, Accreditation Canada adopted a new survey 1 methodology, known as Qmentum, which assesses the degree to which its standards are embedded into daily practice. ${ }^{1}$ The Qmentum standards include Required Organizational Practices (ROPs), which are practices that must be in place to enhance patient safety and to minimize risk.

Health authorities across Canada face significant challenges in assessing their degree of readiness for an Accreditation Canada survey. Conducting an environmental scan is difficult, because both practices and cultures differ across sites and across patient care units. Assessing readiness is further complicated by variability in how pharmacy managers, hospital administrators, and accreditation surveyors may interpret the standards and how "compliance" may be accomplished.

\section{CHALLENGES IN MEASURING READINESS FOR ACCREDITATION}

Preparing for accreditation under the new Qmentum model is extremely challenging. Organizations can no longer "hide" behind written policies to receive accredited status. Instead, it is now necessary to actively demonstrate that Qmentum standards have been incorporated into the daily practice of all disciplines across all programs at all sites. The Qmentum methodology involves accreditation surveyors directly observing daily practice at all levels, including interactions between front-line staff and patients. As a result, surveyors are able to see and assess what practice actually is, rather than what it is thought to be or what it should be.

Planning for a successful survey requires that the scope of effort be defined and managed within available resources. The Fraser Health Authority in British Columbia has 12 sites and 17 regional programs, with vast distances between sites. Given that all components of each ROP must be fully implemented throughout an organization if the organization is to receive full accreditation status, the pharmacy department made a strategic decision to initially focus only on medication-related ROPs, rather than attempting to address all of the constantly evolving Managing Medications standards (see Appendix 1, available online at www.cjhp-online.ca/index.php/cjhp/issue/view/81/ show $\mathrm{Toc})$. This focused approach enabled the department to prepare for the survey within available resources.

The next step required an environmental scan of each site to determine the following characteristics:

- the degree to which each patient care unit had addressed each of the medication-related ROPs

- the strategies that had been applied to achieve compliance

- the sites or patient care units that required priority assistance to achieve compliance

To proceed with the environmental scan, standardized interpretations of the ROPs and a tool for data collection and analysis were required. Each ROP is generally written in broad language to describe the desired practice change, allowing for a variety of interpretations, depending on the viewpoint and expertise of the individual. As such, it was necessary to establish clear definitions that were specific, measurable, actionable, and relevant to patient care and medication-related processes. Without a standard, consistent interpretation of the ROPs, the resultant subjectivity in data collection and rating would have rendered any roll-up of the data uninterpretable. These standardization processes were facilitated by a regional pharmacy coordinator (J.M.) who had recognized expertise in both medication safety and the accreditation survey process. Regional definitions were developed for the following components:

- standard interpretation of each ROP (see Table 1 for an example)

- options that could be considered to achieve compliance (see Table 2 for an example) (for some ROPs, a variety of options were deemed acceptable, since no single option was appropriate for all practice situations at all sites)

- $\quad$ ratings of progress and compliance status (Appendix 2, available online at www.cjhp-online.ca/index.php/cjhp/ issue/view/81/show Toc) 
Table 1. Example of Standard Interpretation of a Required Organizational Practice (ROP)

\begin{tabular}{|c|c|c|}
\hline Safety Issue & Accreditation Canada ROP & $\begin{array}{c}\text { Interpretation of } \\
\text { Fraser Health Authority }\end{array}$ \\
\hline $\begin{array}{l}\text { Concentrated potassium } \\
\text { solutions }\end{array}$ & $\begin{array}{l}\text { - Ensure the safe use of high } \\
\text { risk medications } \\
\text { - Remove concentrated } \\
\text { electrolytes (including, but } \\
\text { not limited to, potassium } \\
\text { chloride, potassium } \\
\text { phosphate, sodium } \\
\text { chloride }>0.9 \% \text { ) from client } \\
\text { service areas }\end{array}$ & $\begin{array}{l}\text { - Remove concentrated } \\
\text { potassium solutions } \\
>2 \mathrm{mmoL} / \mathrm{mL} \text { (i.e., vials of } \\
\text { potassium phosphate, } \\
\text { potassium chloride) from } \\
\text { patient care units and night } \\
\text { cupboards }\end{array}$ \\
\hline
\end{tabular}

Table 2. Acceptable Options for Compliance with Required Organizational Practice (ROP) for Potassium Phosphate*

\begin{tabular}{|c|c|}
\hline Strategy & Action \\
\hline Full compliance with ROP & No action required \\
\hline Option A & $\begin{array}{l}\text { Purchase premixed solutions from the manufacturer and } \\
\text { dispense upon receipt of a patient-specific order }\end{array}$ \\
\hline Option B & $\begin{array}{l}\text { Purchase premixed solutions from the manufacturer and } \\
\text { provide limited quantities as ward stock }\end{array}$ \\
\hline Option C & $\begin{array}{l}\text { Mix potassium phosphate solutions in pharmacy upon receipt } \\
\text { of orders that have been reviewed by a pharmacist }\end{array}$ \\
\hline Option D & Provide vials of sodium phosphate to patient care units $\ddagger$ \\
\hline Site-specific alternative & $\begin{array}{l}\text { Preapproval by regional medication safety coordinator } \\
\text { required for any site-specific alternative }\end{array}$ \\
\hline \multicolumn{2}{|c|}{$\begin{array}{l}\text { *This example is specific for potassium phosphate. Similar tables of options exist for each of } \\
\text { the ROPs. } \\
\text { †Some options afford a higher level of safety. Options are presented in decreasing order of } \\
\text { best practice (in the opinion of the regional medication safety coordinator). } \\
\text { fThis substitution (of sodium phosphate for potassium phosphate) may require converting } \\
\text { orders for the potassium salt to the sodium salt, either by consultation with the prescriber or } \\
\text { by development of an approved automatic substitution policy. }\end{array}$} \\
\hline
\end{tabular}

The health authority subsequently approached Accreditation Canada, seeking endorsement of the standardized interpretations; however, given Accreditation Canada's broad mandate, local interpretation of the standards was deemed outside its scope of activities.

\section{BUILDING AN ROP TRACKING TOOL}

To facilitate data collection and analysis, the pharmacy department developed an in-house integrated "dashboard" tool, the ROP Tracking Tool, to monitor accreditation-readiness for each of the medication-related ROPs across the health authority. The ROP Tracking Tool enabled local sites to submit data based on the standardized definitions. Linkages between components of the tool and strategies for "rolling up" the data were used to generate customized reports, which in turn informed the assessment of accreditation readiness and guided subsequent interventions. A review of the literature did not identify any pre-existing tools serving a similar purpose and function.
Conceptual design work of the tracking tool began once the standardized ROP definitions, acceptable options, and rating scales had been established. Guiding principles were developed and served as a template for design of the tracking tool (Box 1). Microsoft Excel was selected as the base platform for the tool, given general familiarity with this product.

To enable unimpeded, simultaneous entry of data, a customized, site-specific data entry workbook was provided to each site. Each of these site-specific workbooks automatically linked its data to 4 distinct health authority-wide dashboards, which in turn generated overviews of ROP status by site, by health authority, and by options selected.

Given the cross-sectional nature of the various data roll-up strategies, the ROP Tracking Tool required that every patient care unit at every site be rated. As an example, a critical care unit at one site would rate its compliance status against each of the ROPs, and these data would feed into an analysis of ROP compliance within the site, across the health authority, and potentially across the various critical care programs in the health authority. 


\section{Box 1. Guiding Principles}

Simple and intuitive in function:

- For raters

- For reviewers

Addresses reporting needs of end users:

- administrators and site leads

- medication safety leads

Visually intuitive presentation:

- Colour-coded dashboard

- Pie-chart quantification

- Comparisons (by ROP, by site, by patient unit)

Dynamic and timely data:

- "Live" data input

- "Instant" reporting capability

"Drill-down" and "roll-up" functionality:

- Down to level of sites or patient care units

- Easy movement between levels

Flexible to changes:

- Easy to update when required (e.g., ROP definitions, descriptions of patient care units, options for compliance)

- Adjustable thresholds for compliance (e.g., 90\%, 100\%)

$\mathrm{ROP}=$ required organizational practices.

Given the complexity of the Excel workbooks and the thousands of embedded data linkages and formulas, it was imperative that the ROP Tracking Tool be easy to work with, yet indestructible. To enhance the user-friendly nature of the tool, prompts were provided at every step of the data-entry process, with ready "one-click" access to a detailed online instruction manual. Extensive use of pop-up text boxes and forced functions ensured that data entry was performed correctly. Moreover, the workbooks were password-protected for security, and each user was given access to only those cells that required data entry. All other cells were locked and protected from inadvertent overwriting of cell contents. Screen shots of standardized data entry pages applicable for each of the ROPs appear in Appendices 3 and 4, available online at www.cjhp-online.ca/index.php/cjhp/issue/view/81/showToc).

The main purpose of the ROP Tracking Tool was to generate reports analyzing compliance status and guiding further action. Because each of the ROPs was rated for every patient care unit, all reports in the ROP Tracking Tool, such as site-specific dashboards, health authority dashboards, and other types of analyses, were generated from the same database set. The full strategy for generation of reports is outlined in Appendix 5 (available online at www.cjhp-online.ca/index.php/ cjhp/issue/view/81/showToc).

To enhance the visual overview, each cell within the dashboard was converted to a simple "red-yellow-green" status colour, according to a set of predetermined rules. The dashboards were designed to operate in real time. As such, whenever data were updated at one site, all linked dashboards were automatically updated to the appropriate colour (i.e., status).
It is recognized that complex workbooks can be challenging to update and maintain if not designed to accommodate changes. Variables such as ROP definitions, options for ROP compliance, and bed assignments can change frequently, so it was deemed desirable that all non-data-related changes be updated in a simple, centralized, "behind-the-scenes" manner. In our ROP Tracking Tool, there are 12 linked workbooks, each with 20 internal worksheets. Without a predetermined design strategy, a single change would have required at least 240 manual changes, rather than just one. The full strategy for centrally updating the ROP Tracking Tool is outlined in Appendix 6 (available online at www.cjhp-online.ca/index.php/ cjhp/issue/view/81/showToc).

\section{TYPES OF REPORTS WITHIN THE ROP TRACKING TOOL}

Seven types of reports are available within the ROP Tracking Tool, to provide information at the site level or at the regional (health authority) level (see Appendix 5).

At the sites, pharmacy managers and hospital administrators can quickly review the site-specific dashboard to determine where to immediately focus resources (Appendix 7, available online at www.cjhp-online.ca/index.php/cjhp/issue/view/81/ show $(0 c)$. ROPs with green or yellow status are of little immediate concern, whereas ROPs with red status require priority attention. A site-based administrator or pharmacy manager can quickly identify "problem" ROPs across the facility (Appendix 8 , available online at www.cjhp-online.ca/index.php/cjhp/issue /view/81/showToc) or can identify specific patient care units that appear to be having difficulty with several of the ROPs. These specific units may have unique circumstances that warrant attention, which the administrator or manager may choose to investigate further. Given that the entire data input process required 3 to 4 hours for a given site, pharmacy managers reported that the ROP Tracking Tool enabled effective, evidence-based prioritization of interventions that saved time and enhanced credibility.

Similarly, regional pharmacy managers can quickly review the health authority dashboard to identify problem sites or problem ROPs across the health authority (Appendix 9, available online at www.cjhp-online.ca/index.php/cjhp/issue/ view/81/showToc). They can also analyze any specific ROP in more detail through the visual assistance of pie charts (Appendix 10, available online at www.cjhp-online.ca/ index.php/cjhp/issue/view/81/showToc), which in turn can provide the regional managers with a quantitative overview of ROP status from the health authority's perspective or a sitespecific perspective. Hyperlinks from these pie charts enable managers to immediately view specific details in specific site workbooks, if required. 
Pharmacists with a regional responsibility for medication safety can analyze any of the ROPs from the perspective of which strategy was used to achieve compliance for any of the specific ROPs (Appendix 11, available online at www. cjhp-online.ca/index.php/cjhp/issue/view/81/showToc). This overview can be useful if standardized practice is being considered or if an attempt is being made to identify common barriers that require a regional strategy. Hyperlinks to each of the sites allow the regional safety coordinators to view data entered at the sites to obtain further detail, if required.

A unique feature of the regional dashboard is functionality to set thresholds for compliance and noncompliance at the regional or site level. In other words, thresholds can be set centrally and applied consistently across the health authority. For example, if it is unacceptable for any patient care unit at any site across the health authority to be in noncompliance with any of the ROPs, the regional threshold for noncompliance can be set at $0 \%$. In doing so, noncompliance within even one patient care unit anywhere in the health authority would automatically flag "noncompliance" for that particular ROP, and managers can quickly identify the site or sites with patient care units not in compliance. Because these thresholds are applied to all sites in real time, the cell colours on all dashboards change immediately, enabling pharmacy managers to quickly analyze and address each situation.

Although real-time functionality enables timely analysis, it is limited in its ability to detect trends. Therefore, periodic snapshots of the data are required to maintain data archives. Another limitation is that maintenance and customization of the ROP Tracking Tool require advanced skills in Microsoft Excel.

Although the ROP Tracking Tool has been populated with information specific to Accreditation Canada's medicationrelated ROPs, it can be easily adapted to track the implementation of any health authority-wide initiative, regardless of whether it is related to accreditation. A simple one-step centralized mechanism updates the common nondata components within the numerous workbooks that constitute the ROP Tracking Tool.

The ROP Tracking Tool is currently built on a Microsoft Excel platform and performs in a manner similar to that of a database. Migration of this tool to a Microsoft Access platform might make the ROP Tracking Tool even more robust, by taking advantage of the advanced report-generating functionality of Microsoft Access.

\section{CONCLUSIONS}

Assessing a health organization's degree of readiness for an upcoming Accreditation Canada survey is a daunting task, given the number of variables that affect practice and the actual process of rating practice.

The ROP Tracking Tool is a dashboard tool built on a Microsoft Excel platform that enables a quick overview of current status of ROP compliance within and across multiple sites of a large health authority. This tool can assist in determining the degree of readiness for an accreditation survey and can help the institution to prepare for the survey, by identifying potential areas of focus and priority. Numerous linkages between workbooks within this tool enable roll-ups for highlevel assessment and drill-down for detailed information.

The up-front establishment of standardized definitions is critical to the functionality of the ROP Tracking Tool. Given that all data are first rated at the level of the patient care unit and then rolled up to a dashboard overview, this template is easily adaptable for other uses.

The authors are willing to share their work and experience with readers interested in using this tool to prepare for accreditation surveys at their own institutions. See the correspondence block at the end of the article for contact information.

\section{Reference}

1. Qmentum [overview]. Ottawa (ON): Accreditation Canada; [cited 2010 Jun 1]. Available from: www.accreditation.ca/accrediation-programs/ qmentum

Mits Miyata, BSc(Pharm), ACPR, is the Pharmacy Director, Lower Mainland Pharmacy Services, Langley, British Columbia.

Janice Munroe, BSC(Pharm), was, at the time the ROP Tracking Tool was created, the Regional Medication Safety Coordinator for the Fraser Health Authority. She is now the Regional Medication Safety Coordinator for Lower Mainland Pharmacy Services, Langley, British Columbia. She is also a surveyor for Accreditation Canada.

\section{Address correspondence to:}

Mits Miyata

Pharmacy Director

Lower Mainland Pharmacy Services

c/o Regional Pharmacy Administration

8521-198A Street

Langley BC V2Y OA1

e-mail: mits.miyata@fraserhealth.ca or janice.munroe@fraserhealth.ca 